RESEARCH ETHICS

\title{
HIV prevention research and global inequality: steps towards improved standards of care*
}

\author{
K Shapiro, S R Benatar
}

J Med Ethics 2005;31:39-47. doi: 10.1136/jme.2004.008102

Intensification of poverty and degradation of health infrastructure over recent decades in countries most affected by HIV/AIDS present formidable challenges to clinical research. This paper addresses the overall standard of health care (SOC) that should be provided to research participants in developing countries, rather than the narrow definition of SOC that has characterised the international debate on standards of health care. It argues that contributing to sustainable improvements in health by progressively ratcheting the standard of care upwards for research participants and their communities is an ethical obligation of those in resource-rich countries who sponsor and implement research in poorer ones.

See end of article for authors' affiliations

Correspondence to:

Correspondence to:
S R Benatar, Department of Medicine \& Bioethics

Centre, University of Cape

Town Observatory, 7925,

Cape, South Africa;

sbenatar@uctgsh1.uct. ac.za

Received 22 January 2004 In revised form 20 May 2004 Accepted for publication 24 June 2004
$\mathrm{F}$ orty million people are now living with human immunodeficiency virus/acquired immune deficiency syndrome (HIV/AIDS), an estimated five million of whom became infected in 2002. ${ }^{1}$ Most live in resource-poor countries where access to basic health care, adequate nutrition, and water are severely limited, annual per capita income is typically less than US\$200, and annual per capita health expenditure below US\$10. ${ }^{2}$

\section{HIV/AIDS RESEARCH IN A GLOBAL CONTEXT}

Spectacular growth of the global economy and inspiring scientific advances in recent decades have led to great hopes that research and further economic growth will improve global health. However, scientific progress, even in association with massive economic growth has proved insufficient to prevent millions of premature deaths from childbirth, malaria, tuberculosis, and diarrhoeal disease-and disparities in health continue to widen. ${ }^{3}$ The burden of HIV/AIDS, more complex in both health and social terms, has continued to grow relentlessly despite advances in prevention and treatment.

Recent ethics discussions have focused on the standard of health care (SOC) in relation to drugs in trials where a placebo arm is under consideration. Detailed reasoned responses to this issue have been provided elsewhere. ${ }^{4-6}$ Here we are concerned with standards for the overall provision of health care to participants in research in developing countries independent of treatment or control arms, an issue that has received less attention but is important in the context of HIV prevention trials.
We first review challenges facing HIV researchers in developing countries. We then redefine SOC in broader terms and argue that contributing to sustainable improvements in health is an ethical obligation of those in resource-rich countries who sponsor and implement research in poorer ones. We describe clinical trials where this has been achieved, and propose steps for implementation of a broader SOC more widely, so that research participants and their communities could be left better off after a trial, and not merely "no worse off". 7

\section{CHALLENGES FOR RESEARCHERS AND HOST COUNTRIES}

International collaborative multisite research on HIV prevention interventions such as vaccines, microbicides, sexually transmitted infection (STI) control, and behavioural and antiretroviral interventions comprise some of the ongoing efforts to prevent spread of new infections. In resource-poor countries such research may require costly inputs by sponsors into local health infrastructure, including building repair, installation of running water and toilets, sophisticated laboratory and computer equipment, staff training, and basic medical supplies. These improvements tend to benefit the research project but leave the public facility where research is housed to deal with its ongoing problems using often meagre resources. Innovative means of attracting additional funds, and even utilisation of a small portion of research funds for treating other diseases afflicting research subjects and improving local health services, in association with research in host countries is important for many reasons discussed later in this paper. However, specific challenges are generated that need to be addressed in the interests of justice and beneficence:

- Where services are improved in the research context, a dual SOC results within a community. Research participants may have easy access to free health care for problems unrelated to the research, in contrast with long waits and lack of essential supplies in the public system. Although some argue that participants deserve better care because of risks taken and time spent in research activities, providing this results in significant problems within families and health facilities.

*This article was developed in conjunction with the Ethics Working Group of the HIV Prevention Trials Network Ethics. 
- Higher SOC than otherwise available may be seen as an undue inducement to participate in a trial. However, access to health care when this is otherwise unavailable is arguably valuable enough to outweigh what are understood to be risks of participation.

- Improved care tailored to research is often expensive and not sustainable at the conclusion of a trial, with the result that research participants lose access to a level of care they had previously enjoyed. Hence the need to consider issues of sustainability.

- Higher quality research-only services given by less burdened providers contribute to perceptions of a cadre of privileged research staff among non-study clinicians. Higher salaries paid to research clinicians are not sustainable and drain the most qualified health workers away from the public sector. The provision of health care for diseases unrelated to the research may contribute to the therapeutic misconception by promoting the erroneous belief that the purpose of the research is to provide beneficial care. Clear communication could minimise these problems.

- Sponsors often stipulate that research funds cannot be used to provide services. Conversely, aid programmes are often restricted from funding research. Cooperation between these activities could enhance the value of both.

- Research on preventive HIV interventions requires large cohorts of high risk, uninfected individuals from vulnerable populations, generating tension between advancing the scientific agenda (for the benefit of future patients) and protecting healthy subjects from research related harms. The question of whether those found to be positive at screening or those who convert during the trial should be treated with antiretrovirals is a further challenge.

- Entire communities may be stigmatised by the mere fact that AIDS research is being conducted because of publicity around large, noticeable trials.

Researchers have anguished over these questions, solutions to which must be sought from sponsors, their governments, and host country governments and not only from front line researchers. ${ }^{8}{ }^{9}$ Commonly, in developing countries researchers cope with inadequate care available to participants and families by extending themselves to assist with health problems unassociated with the research. The motivation of researchers to provide more complete and compassionate services deserves encouragement and support from sponsors. Improved care is often cited as a reason for participation in trials and also contributes to study accrual and retention. However, such services barely meet participant needs, much less the larger unmet need for care in the community. Improved access to antiretrovirals through the World Health Organization's (WHO's) initiative to treat three million with AIDS by 2005 could make moot the dilemma about antiretrovirals for seroconverters during trials. However, the failure of donors to provide funding for " 3 by 5 " means that the dilemma will persist until there is universal access to antiretroviral therapy (ART). Despite good intentions, well resourced, research sponsored care in an otherwise impoverished healthcare facility is a microcosm of global health inequities that challenges researchers and sponsors to promote the ideals of justice aimed for in international ethics declarations.

WHAT STANDARD OF CARE, WHOSE DEFINITION? Debate about the standard of care in international research ethics has to date centred on what standard of drug treatment is acceptable in the control arm of a randomised controlled trial (RCT). This debate about SOC as the best proved drug treatment excludes consideration of context and essential "background" elements of health care to which participants and the surrounding community in developed countries normally have access, all of which are relevant to the standard of care related to the research project. The perspectives on the key issues relating to SOC in five international research ethics documents ${ }^{71-13}$ (summarised in table 1) reveal that the phrase "standard of care" is often addressed obliquely and remains poorly defined. These international guidance documents thus do not sufficiently address the broader concept of SOC that constitutes the thrust of this paper.

The definition of SOC in research that we propose lies somewhere between the highest standard achievable with unlimited resources and the miserably low (sometimes nonexistent) standards characteristic of very poor countries. Some may resist broadening the definition of SOC in this way, preferring to consider additional care as ancillary to research. Others, however, agree that even ancillary care (not directly related to research) should be provided when certain well defined circumstances exist, and have recently proposed a framework to better define when and how such obligation exists. ${ }^{14}$ We contend that research cannot be considered in a vacuum, and that the role of the researcher in developing countries differs from that role in resource-rich countries where research participants generally have access to adequate health care. We argue that by implementing progressive improvements in the level of health care of research participants, the overall standard of health care could be ratcheted upwards-thus providing a link between research and health care.

\section{ARGUMENTS FOR IMPROVING THE STANDARD OF HEALTH CARE}

Arguments for improving the overall standard of care in association with research projects can be advanced from several different but interlinked perspectives.

\section{Justice}

The principle of distributive justice in the research context requires that the burdens and benefits of research be fairly distributed among all involved. The concept of justice is explained "as fair, equitable, and appropriate treatment in light of what is due or owed to persons". People are due or owed benefits or burdens because of "being productive or having been harmed by another person's acts". ${ }^{15}$ Differences between SOC available in host and sponsor countries are often inherently unjust for the following reasons:

- Poor communities may bear the burden of research but not benefit from it because of the complexities of the poverty in which they exist.

- Although those in rich sponsoring countries may not benefit directly from HIV prevention research conducted in poor countries, they also bear little if any of the burden of that research and often benefit indirectly from academic and other recognition.

- Factors contributing to poverty, disease, and poor health in developing countries are in part attributable to previous or current actions of sponsoring countries-colonialism, exploitation of cheap labour and natural resources, support of corrupt regimes, sustaining levels of unpayable foreign debt, and unsound trade rules - that are beyond the control of local governments alone to address.

- Researchers are generally privileged people, while many research participants are among the most vulnerable in our world, living under the worst conditions of deprivation. ${ }^{16}$ 


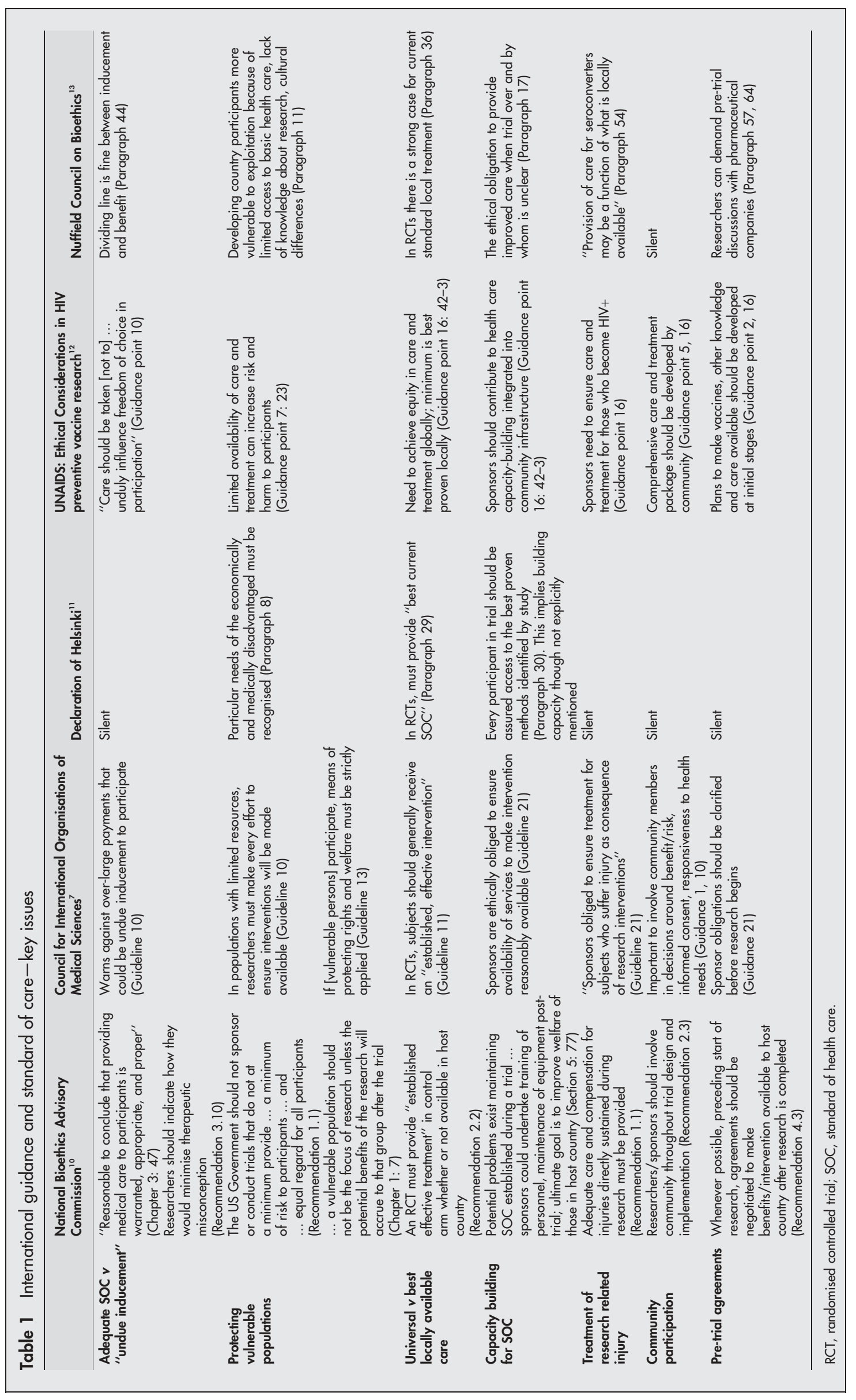


Table 2 The burdens and benefits of international research

\begin{tabular}{|c|c|c|}
\hline & Burdens & Benefits \\
\hline Participants & $\begin{array}{l}\text { Risk to health-iatrogenic } \\
\text { Stigma and social harms } \\
\text { Time lost to visits } \\
\text { Risk of exploitation } \\
\text { Increase in risk behaviour if mistaken belief that study is } \\
\text { protective }\end{array}$ & $\begin{array}{l}\text { Improved healthcare access } \\
\text { Improved health status } \\
\text { Increased knowledge about health } \\
\text { Feeling of altruism } \\
\text { Benefits of positive results if available }\end{array}$ \\
\hline Community & $\begin{array}{l}\text { Poor overall access to care in the presence of increased } \\
\text { resources for research } \\
\text { Dual SOC with access only to the lesser standard by non-participants } \\
\text { Stigma of identification with HIV infection }\end{array}$ & $\begin{array}{l}\text { Improved access to care if resources shared } \\
\text { Increased knowledge about health } \\
\text { Benefits of positive results if available }\end{array}$ \\
\hline Healthcare system & $\begin{array}{l}\text { Diversion of scarce health resources to research: } \\
\text { - health workers } \\
\text { - clinic and hospital space } \\
\text { - materials } \\
\text { Dual standards of care } \\
\text { Increasing fragmentation of services } \\
\text { Research priorities may dominate services }\end{array}$ & $\begin{array}{l}\text { New resources for health } \\
\text { Training for health workers } \\
\text { New clinic and hospital space }\end{array}$ \\
\hline $\begin{array}{l}\text { Researchers from } \\
\text { sponsoring country }\end{array}$ & $\begin{array}{l}\text { High costs } \\
\text { Operational complexities } \\
\text { Regulatory restrictions } \\
\text { Cultural and social gaps in understanding population }\end{array}$ & $\begin{array}{l}\text { Career advancement } \\
\text { Good salaries } \\
\text { Travel to interesting places } \\
\text { Right livelihood, altruism }\end{array}$ \\
\hline $\begin{array}{l}\text { Researchers from } \\
\text { host country }\end{array}$ & $\begin{array}{l}\text { Sponsoring country researcher may set research agenda } \\
\text { Cultural and social gaps in understanding } \\
\text { Racism } \\
\text { Divided loyalties between local and sponsoring institutions }\end{array}$ & $\begin{array}{l}\text { Career advancement } \\
\text { Altruism } \\
\text { Increased resources for research directed to local } \\
\text { problems } \\
\text { Higher salary than if locally funded }\end{array}$ \\
\hline Sponsors & $\begin{array}{l}\text { Failure to recover costs } \\
\text { Potential for external problems stalling project } \\
\text { Operational complexities } \\
\text { Regulatory complexities }\end{array}$ & $\begin{array}{l}\text { High profit potential in drug research } \\
\text { Less stringent ethical oversight } \\
\text { Lower operating costs } \\
\text { Improved public profile of company or organisation }\end{array}$ \\
\hline
\end{tabular}

Faced personally with the dehumanising conditions under which their research participants live, many researchers feel motivated to ameliorate social injustice through contributing to an improved SOC, often at personal expense.

It would be undisputed that research initiatives themselves should not introduce new inequalities or further exacerbate existing inequalities in health in the community where research is being conducted. Moreover, in the absence of an adequate theory of international distributive justice it remains feasible to seek to reduce gross injustices through reasonable means. We agree with the cogent arguments advanced by Pogge that richer sponsoring countries (governments, aid agencies, academic institutions, and the pharmaceutical industry) have an ethical obligation to transfer resources to poorer nations on the grounds that they are intimately involved with sustaining such poverty. ${ }^{17}$

\section{Beneficence}

This principle requires that researchers take some responsibility for participants' physical, mental, and social wellbeing as related to the study. ${ }^{18}$ Although ethicists argue about the limits of obligatory beneficence, we agree with Singer that "if it is in our power to prevent something bad from happening without thereby sacrificing anything of comparable moral importance, we ought morally to do it". ${ }^{19}$

\section{Defining limits}

Contrary to the views of some that distributive justice and beneficence require continued transfer of resources so long as disparities exist, we believe that reasonable lines can be drawn. For example transfer of merely $1 \%$ of the resources of the richest $20 \%$ of the world's population to the poorest $20 \%$ would almost double their annual per capita gross national product (GNP). With this in mind we recommend that a minimum of $1 \%$ of the cost of a research project be allocated towards improving the SOC in association with the project. If more can be generated through the partnerships we describe below so much the better. We do not unrealistically propose that research be shackled by excessive demands for associated medical care. We do suggest that conducting research as though in a vacuum, oblivious to the basic health needs of research participants in developing countries, does not meet the ethical requirements of justice and beneficence. Requiring greater sensitivity to the plight of the poor and some degree of solidarity with them is not an excessive moral requirement. Living in South Africa during the apartheid era sensitised one author of this paper to the moral burden of bearing witness to gross inequalities and prompted many to strive to narrow disparities under difficult conditions. The value placed on openly bearing witness and providing humane support to some of the most marginalised people on earth is reflected in the award of a Nobel Peace Prize to Médecins Sans Frontières in 1999. Upholding the ethical integrity of researchers, particularly the caring role of doctors in the role of researchers, requires that they be supported and encouraged by sponsors with adequate funding and staff to form enduring relationships with their host country and international partners. Facilitating beneficence in this way can also contribute towards more equitable distribution of burdens and benefits.

\section{Strategic interest}

Today's emerging infectious diseases have no respect for any national boundaries and are now widely recognised as global threats. The long term self interests of all would thus be better served by working collaboratively to provide a decent minimum SOC across the globe (including to the $20 \%$ of US citizens with inadequate access to health care). ${ }^{2021}$

\section{Capacity building}

An adequate SOC presents an opportunity for continuity, a link between research, the promise of improved health care, and a firm foundation for future research. Table 2 illustrates 


\section{Box 1: Case study 1}

HIVNET 012 was a pivotal trial in Kampala, Uganda that established the efficacy of oral nevirapine given to HIV infected mothers and their infants to Prevent Mother to Child Transmission (PMTCT) of HIV. ${ }^{22}$ During this trial, which was conducted in 1997-99, participants were offered easy access to primary health services and free treatment. Researchers have gone on to coordinate funding through the Elizabeth Glaser Pediatric AIDS Foundation, helping to create the "Call to Action Project" which makes funds available for implementation of nevirapine projects and infrastructure building in resource-poor settings throughout the world. ${ }^{23}$ Nevirapine is now background SOC for numerous other perinatal studies being implemented. Implementation of nevirapine for HIV infected pregnant women in the research setting requires trained counsellors to conduct voluntary counselling and test (VCT), providers to improve management of pregnancy, labour and delivery, provide better infection prevention intrapartum, counsel the mother immediately postpartum on infant feeding and provide long term support, counsel the partner, and make efforts to reduce the stigma of HIV infection among mothers and their families.

These elements of care require training of maternity staff and low technology inputs such as running water, electricity, soap, bleach, gloves, and private areas for counselling. As PMTCT research becomes national policy and moves to implementation of programmes, these relatively modest efforts can make an important contribution to improving maternal and child health outcomes and decreasing vertical transmission. The next step now being implemented is PMTCT Plus, the addition of care and support for infected mothers, including antiretrovirals.

factors that must be weighed to achieve a balance between burdens and benefits of research.

\section{RATCHETING STANDARDS UPWARDS: THREE CASE STUDIES}

Despite considerable challenges facing researchers, there are successful examples of clinical trials that have left sustainable, local improvements in the standard of care; we present three (boxes 1-3). With time and resources spent on creating partnerships, research activities strengthened the local prevention and care infrastructure in Mwanza and Lilongwe. In Kampala, strengthened services paved the way for a local and global programme for implementation of research results.

The challenges are, however, ongoing and resources inadequate. Follow-on programmes in Uganda have been managed by research staff alone, without either training or payment for added work. Highly committed staff feel that lacking additional personnel and resources, the research they are trained to conduct will suffer if local staff are not able to take over programme management. Tragically, while newly pregnant infected women in Kampala are eligible for antiretrovirals through the PMTCT Plus Project, of the 500 HIV infected women who participated in HIVNET 012 over $90 \%$ remain without them four years later because they do not fit into any project category which would have given them access, despite the untiring efforts of researchers to secure drugs.

In Lilongwe, building on the success of trials funded by the HPTN, the UNC has launched its Call to Action programme, offering VCT and single dose nevirapine to all pregnant women in the Lilongwe area, regardless of trial participation.

\section{Box 2: Case study 2}

At Lilongwe Central Hospital in Lilongwe, Malawi, the HIV Prevention Trials Network (HPTN) a collaborative, multisite research network sponsored by the National Institutes for Health (NIH), is implementing multiple randomised controlled trials in the next one to two years. Considerable inputs of sponsor funds are being used to improve research capacity and infrastructure. University of North Carolina (UNC) researchers and Malawian coinvestigators have created a dynamic partnership to transform research into programmes and to integrate research and programme infrastructures. In 1997, a group of clinicians started a volunteer organisation called Lighthouse, in response to rapidly escalating rates of HIV/AIDS. They trained 150 community volunteers in home based care, VCT and clinical outpatient care. Lighthouse now has support from multiple sources, including the UNC, Lilongwe Central Hospital, local donors, the European Union, the Norwegian Aid Agency, the Centers for Disease Control in the USA, Macro, an US funded agency, the Global Fund (GFATM) and the Diana Princess of Wales Fund. The UNC provides one full time doctor and the services of three other doctors for one day each every week. Lighthouse clinicians also work for the UNC Project, and Lilongwe Central Hospital, the public teaching hospital where research occurs. Lighthouse has just moved into a new, large, fully equipped outpatient HIV/AIDS clinic adjacent to the hospital and is the centre of the government's subsidised ART programme in Lilongwe. The majority of Malawians who require care cannot afford ART, but those who have access to Lighthouse are given supportive counselling, treated with appropriate medications for opportunistic infections and pain, and supervised home based care, free of charge. Lighthouse recruits participants for HPTN trials, treats them and their families, and other Malawians infected or affected by HIV/AIDS. Lighthouse can serve only a fraction of those infected in Malawi but it provides a synergistic model to build upon to improve SOC throughout the country; the belief that providing health related services to clients enhances the productivity of related clinical research likewise provides a model on which other researchers can build to improve both the lives of their participants and the quality of their research.

In one year, the programme has offered PMTCT services to over 8000, but logistical problems continue to limit the numbers who have actually received VCT and nevirapine.

In Mwanza, insufficient government support for scaling up the intervention to the entire province resulted in lack of monitoring of newly trained health workers and low availability of drugs for treatment. Resulting decreases in the quality of care at primary health centres were found on a subsequent evaluation. These challenges make clear the need for sustained commitment to improving SOC to prepare for implementation of positive research results. Without this commitment, communities are often left to conclude that research in which they willingly participated gave them nothing in return.

Researchers themselves cannot shoulder the burden of coordinating high level partnerships and programmatic changes; what researchers do best is research. Sponsors and their governments must insist on allocation of funding and staff for these activities, with the political will and appropriate resources of host country governments and through suitable partnerships. By improving the SOC and extending it to the broader community, research can help bridge the unacceptable gap between the SOC in sponsoring countries 


\section{Box 3: Case study 3}

In Mwanza, Tanzania, a large community randomised trial funded by the British Medical Research Council was conducted from 1991 to 1994 in six matched rural community pairs. ${ }^{24}$ The intervention consisted of improved case management of sexually transmitted diseases (STDs) at district health centres and dispensaries in the experimental arm. The intervention was integrated into existing district primary health care using available staff and health units. This involved training of government health workers in syndrome management, improved management of essential drugs for STD treatment, community education and raising of awareness of symptoms, the need to seek care, and HIV prevention activities-basic, sustainable and low cost improvements to the existing public healthcare system. Rural health units were provided with essential equipment where this was not available-examination beds, sheets, screens, benches, stools, and wooden boxes to store drugs, all locally produced. A reference clinic for patients with STDs not responding to treatment was established at the hospital in Mwanza and integrated into the outpatient department. Control communities received existing "standard of care" but were assured of availability of drugs. At the end of the trial, intervention communities achieved a $38 \%$ reduction in HIV incidence compared with controls. The improved STD care approach was immediately extended to control communities and subsequently to the entire province as a result of combined efforts of the research team in partnership with district and national health leadership.

and that of the countries where the AIDS burden is highest and where the research is conducted.

\section{STEPS TOWARDS IMPROVED STANDARD OF HEALTH CARE}

We argue that SOC should be based on principles that promote fairer distribution of burdens and benefits, both short and long term for participants and communities. Firstly, research should be undertaken in the best interests of trial participants and should involve them in decisions around research design and implementation. Secondly, the dignity of research participants, rich or poor, educated or not, wherever they live in the world should be equally respected, in the sense that they should be treated as ends in their own right and not merely as the means to achieving the ends of others. Thirdly, consideration should be given to the broader community benefit that could be achieved by raising the SOC through partnerships created by the research endeavour. That the ideal of first world health care cannot be achieved immediately in developing countries should not be a deterrent to efforts to raise existing levels of care. By setting high ideals and working towards them, the standard of care could be progressively ratcheted upwards. ${ }^{4525}$ We present seven steps to guide improvements.

\section{Involve the community}

Community consultation is key to identification of elements of care most important to the population where research is conducted. This can be done by identifying community members and involving the community at the start for advice on their research priorities, feasibility of proposed research, raising community awareness of HIV prevention research and HIV itself, including destigmatising HIV/AIDS, through participation in research. The Community Working Group established by the HPTN to support the formation of local community advisory boards (CABs) at each of its research sites, is one example of the concrete steps that can be taken to encourage community participation in research. ${ }^{26}$ The process of defining community and supporting more than token participation takes time, care, and resources. ${ }^{27}$ Researchers and sponsors need to commit time and money to conduct formative research to identify community leaders and needs, and to have discussions with community members, involving them in real decisions, not simply informing them of what is to happen. Other mechanisms used to involve community are the bringing together of community representatives from multisite studies to discuss common issues; circulation of a global community newsletter to those participating in the same multisite studies to share new information; research and ethics training curricula that have been developed with communities and HPTN staff. Training sessions have been conducted which empower community members to participate more fully through greater understanding of scientific and ethical reasoning. ${ }^{28}$ At the same time international research staff have gained much needed insight into the cultural perspectives of participant communities and the real problems they face on a daily basis.

\section{Determine the elements of SOC}

The specifics of the standards of care for a particular project should be determined through consultation among concerned parties (for example, participants, researchers and their collaborators, representatives of local and national health authorities). Elements of care will depend upon the specific nature of the research, local context, need, resources, and documented impact on the community.

The HPTN, in new ethics guidance drafted for its own research, requires systematic assessment of care and services needed to implement research, and accessibility to the outside community, before research begins. ${ }^{29}$ The elements of care outlined in the UNAIDS guidance document should, at a minimum, be provided to study participants and ultimately to their communities. These include: counselling; prevention/treatment of other sexually transmitted infections; tuberculosis prevention/treatment; prevention/treatment of opportunistic infections; nutrition; palliative care including pain control and spiritual care; referral to social and community support, family planning, home based care; and ART. ${ }^{12}$

\section{Form partnerships}

Partnerships are central to integrated and coordinated country strategies to fight the epidemic and have the potential to strengthen AIDS research, prevention, and treatment so that all benefit. ${ }^{27}$ Starting with the community and local and national health authorities, partners who can contribute shared resources for improving care should be consulted-for example, local AIDS care programmes, nongovernmental organisations (NGOs), religious and grassroots organisations, cooperating agencies, workplace programmes, and industry. Early identification of partners could be required when sponsors review grant applications and funding provided in awards to pursue local and international partnerships. Linking prevention research to programmes is an obvious way to build on shared resources and expertise. Collaboration with bilateral and multilateral funders and implementers such as the WHO, the World Bank, the Global Fund for AIDS, Tuberculosis and Malaria, private foundations and international NGOs should be explored. Pharmaceutical industry partnerships for provision of drugs at affordable prices to governments should be pursued as should host country capacity building for manufacture or import of generic drugs according to the Intellectual Property and Trade (TRIPS) agreement provisions, including fixed dose combination antiretrovirals recommended by the WHO. 
For more information on the baffling complexities of the TRIPS agreement and Doha negotiations, readers are referred to the Médecins Sans Frontières' Access to Medicines campaign. ${ }^{30}$ With regret, no progress has been made because the bureaucratic hurdles are many and so complex that noone has been able to negotiate them. Negotiating such partnerships requires knowledge of local and international HIV/AIDS research, programme and donor activities, and the process should be funded by sponsors and host countries to ensure collaboration.

The recently formed HIV Treatment Access Coalition (ITAC) is a broad coalition of partners with the goal of expanding access to HIV treatment for all who need it, recognising that the challenges ahead are "beyond the capacity of any one organisation to solve" ${ }^{31}$ The declaration on 22 September 2003 by the Director General of WHO that the AIDS treatment gap is a global emergency and the launch of activities to treat three million in poor countries by $2005,{ }^{32}$ together with President Bush's emergency plan for AIDS relief (PEPFAR), ${ }^{33}$ are expected to further expand resources for care in the countries in which research on AIDS prevention is conducted.

\section{Provide proved prevention and care}

Ethics guidance documents of the past decade recognise the principle that research conducted in developing countries should be responsive to local health needs. Provision of already proved interventions in communities where new research is conducted makes good on the promise that public health research will actually improve the health of the population. Therefore, interventions shown in clinical trials in resource-poor countries to have an effect on HIV transmission (such as provision of drugs for PMTCT, management of sexually transmitted infections, free condoms, risk reduction counselling, and treatment and prevention of common opportunistic infections with cost effective, essential medicines) should be made available in the context of new HIV prevention research. Unfortunately, this is often not the case-for example, trimethoprim-sulfamethoxazole prophylaxis in patients with AIDS prolongs life and costs a few cents per month but is still not in widespread use. ${ }^{34}$ Directly observed treatment, short course programmes (DOTS) for management of tuberculosis covers only $36 \%$ of Africa $^{35}$ and currently only $1 \%$ of African women have access to nevirapine for PMTCT. ${ }^{36}$ If trial communities rank clean water, food supplements, and housing above medical interventions, sponsors and other partners might contribute to these background improvements in addition to more medicalised interventions. Ensuring baseline standard of living and health care across study sites will also contribute to more generalisable study results.

\section{Antiretroviral therapy}

In the face of maturing AIDS epidemics, lower costs of antiretrovirals, and increased funding for AIDS treatment programmes, the rapidly changing treatment landscape demands consideration. HIV prevention research conducted in countries where millions are already infected cannot ignore those in its midst who are ill. Even while treatment for opportunistic infections remains out of the reach of most infected people in the world, antiretrovirals have come into use in resource-poor settings.

In most sites in developing countries where research on HIV prevention occurs, ART is offered for growing numbers of eligible patients at subsidised prices or through the private sector. Infrastructure to support CD4 testing and monitoring of viral load is already linked to research efforts. Only a fraction of the world's infected have access to ART but the simpler, proved options for AIDS prevention and care listed above should be fully exploited now while access to ART remains limited. This requires training health workers in all aspects of AIDS care, strengthening primary health care, assuring timely diagnosis and treatment of opportunistic infections, improving distribution of essential drugs, and ensuring referrals. Such improvements are the first step towards the addition of more complex, costly therapies. PMTCT programmes can and should be background SOC in any HIV prevention research setting where women are enrolled. In research contexts, focused efforts should be made to contribute towards primary AIDS care (not including ART) to all who require it, not only trial participants. Treatment of pregnant HIV infected women and their infants involved in perinatal trials should be given high priority within whatever services exist.

Should ART be provided to participants who seroconvert during a trial? To many researchers, provision of ART to seroconverters in a trial would open the floodgates to provision of an expensive "universal" standard, which must be provided for the participant's lifetime, thereby making the research prohibitively expensive. Others working in the field in direct contact with people with AIDS believe that they as researchers cannot stand by silently as their participants die of a treatable disease. If and when the broader conception of SOC advocated in this paper is adopted, the question will become moot.

Through research partnerships, decreasing drug prices, and increasing global commitment, ART is rapidly becoming available. Prices as of April 2004 for triple therapy have plummeted to less than US\$150 annually and will go lower; in a trial of 8000 participants where 100 endpoints (HIV infection) are required to demonstrate significant results, the cost of triple therapy for 10 years is US\$150000. This amounts to a fraction (less than $0.4 \%$ ) of the total cost of such a trial, which surely can be borne by sponsors and other partners from resource-rich countries. We know costs will decrease significantly by the time seroconverting participants require treatment. Such a sum set aside in trust at the beginning of a trial to ensure treatment for those who will need it could also be used to augment treatment in the larger community as prices decrease. Of course, ART requires more than drugs alone-but the strengthening of health infrastructure, already a part of research site capacity building, will be a strong foundation for the eventual provision of universal ART aimed at by WHO. ${ }^{37}$ Piloting of ART within the better resourced research setting, with the objective of wider availability to non-participants as knowledge and resources increase, is one way to move forward with the "ratcheting up" process. Support is gathering for such ideas, and their implementation will represent moral progress. ${ }^{38} 39$

\section{Ensure benefits to both participants and community}

Improving SOC for both research participants and their surrounding community addresses the dilemmas of dual standards and undue inducement to participate; more importantly, it contributes to greater global health equity. ${ }^{40}{ }^{41}$ Equitable mechanisms of decision making between the community, researchers, sponsors and health authorities must evolve with the help of staff skilled in participatory planning. Improvements in basic primary care such as improved management of sexually transmitted infection or PMTCT and accompanying improvements in maternal and reproductive health care might gradually be made available for all who come to the facility where research is occurring. Making clear that the improvements are partly a result of the research-host-country-community partnership legitimises what might otherwise be seen as privileged care for a few.

\section{Link research to enhancing justice}

We acknowledge the serious concerns of researchers that the immense need for improved care in resource-poor settings 
Table 3 Benefits of improved standard of care in research

\begin{tabular}{|c|c|c|c|c|}
\hline Healthcare system & Researchers & Communities & Policy makers & Ethics/human rights \\
\hline $\begin{array}{l}\text { Increased resources } \\
\text { for care }\end{array}$ & $\begin{array}{l}\text { Enhanced accrual and } \\
\text { retention }\end{array}$ & Improved health care & $\begin{array}{l}\text { Evidence that new } \\
\text { interventions can be } \\
\text { implemented into healthcare } \\
\text { system, and how } \\
\text { Establishment of partnerships } \\
\text { to implement policy change }\end{array}$ & $\begin{array}{l}\text { Concordance with ethics and } \\
\text { human rights documents }\end{array}$ \\
\hline $\begin{array}{l}\text { Better training for } \\
\text { providers }\end{array}$ & $\begin{array}{l}\text { Improved adherence to } \\
\text { protocol/visit schedules }\end{array}$ & $\begin{array}{l}\text { Increased trust in health } \\
\text { system }\end{array}$ & & $\begin{array}{l}\text { Increased ability to deal with } \\
\text { external challenges to ethics of a } \\
\text { trial }\end{array}$ \\
\hline $\begin{array}{l}\text { Opportunities for } \\
\text { integration of services }\end{array}$ & $\begin{array}{l}\text { Increased trust of } \\
\text { participants and families }\end{array}$ & Increased trust in researchers & $\begin{array}{l}\text { Improved international } \\
\text { relations through } \\
\text { cooperative partnerships }\end{array}$ & $\begin{array}{l}\text { Safeguard for participants from } \\
\text { research related harms }\end{array}$ \\
\hline Opportunities for partnership & $\begin{array}{l}\text { Increased legitimacy } \\
\text { of research }\end{array}$ & $\begin{array}{l}\text { Increased HIV/AIDS health } \\
\text { seeking behaviour }\end{array}$ & & \\
\hline $\begin{array}{l}\text { Opportunities for enhanced } \\
\text { coordination among donors }\end{array}$ & $\begin{array}{l}\text { Possible improved reporting } \\
\text { of sexual behaviour }\end{array}$ & $\begin{array}{l}\text { Increased awareness of HIV } \\
\text { prevention }\end{array}$ & & \\
\hline \multirow[t]{2}{*}{$\begin{array}{l}\text { Better climate conducive to } \\
\text { future research }\end{array}$} & Clearer trial results & $\begin{array}{l}\text { Preparation for implementation } \\
\text { of successful interventions }\end{array}$ & & \\
\hline & $\begin{array}{l}\text { Willingness to enrol } \\
\text { in future trials }\end{array}$ & $\begin{array}{l}\text { Decreased stigma around HIV/ } \\
\text { STDs }\end{array}$ & & \\
\hline
\end{tabular}

has the potential to engulf research priorities. But the moral imperative to do more is already deeply felt by many researchers, and there is merit in the idea that advancing scientific knowledge should not be given a higher priority than reversing gross injustices in global health that exist within the research setting. ${ }^{42}$ A paradigm shift is called for: a transformation of our whole idea of how research is conducted when entering into a relationship with an impoverished people. ${ }^{4}{ }^{16}$ We believe the ethical value and legitimacy of research in developing countries can be greatly enhanced by fostering this linkage of research to enhancing justice $^{25} 43$ (table 3$)$.

\section{Increase funding}

Current practice in the USA requires that government funds allocated for research be used for that purpose alone, and not for unrelated care. Researchers and their institutions can, and some do, use their status to pressure public sponsors such as the NIH (and similar organisations in other countries) for changes. Other mechanisms to increase funding should be sought: public-private partnerships; using electoral and legislative processes to push for more funds to link AIDS programmes and research; soliciting funding through private foundations; and coordination with other aid programmes at research sites.

US academic institutions receive up to $60 \%$ of awards for research as overhead costs, while collaborating resource-poor institutions receive only $8 \%$. If this balance were changed to reflect need, more resources would be available to sites to improve care, especially if an agreed-upon percentage of the total award could be allocated to improve SOC. A requirement by sponsors for a line item in research proposal budgets specifically to contribute to SOC would ensure minimum resources. HIV vaccine researchers in South Africa have proposed creating a trust fund for future treatment of participants who seroconvert in the course of a trial and the HPTN is considering a similar scheme. ${ }^{44}$ Local health authorities that approve of internationally funded studies should make financial commitments to improve public care to ensure programme coherence and sustainability. The World Bank's Multi-country AIDS Program gives grants directly to host countries, which can be used for any AIDS research or programme activities, including care.

Debt relief from the International Monetary Fund and the World Bank would loosen current restrictions on health spending by governments heavily burdened by the AIDS epidemic. ${ }^{45}$ Complex administrative and bureaucratic processes for spending money need to be streamlined. Existing funds, already allocated to countries with high HIV prevalence by the Global Fund to fight AIDS, Tuberculosis and Malaria and the Global AIDS Program, funded through the US Centers for Disease Control, need to be spent and could begin to address the gap in available services between host and sponsor countries.

\section{RECOMMENDATIONS FOR ACHIEVING NEW IDEALS}

Moving away from a concept of SOC that focuses exclusively on drugs to one that progressively embraces considerations outlined above requires several steps. Firstly, sensitivity must be acquired to exploitation and how this is perceived within host countries. Secondly, the will must be summoned to achieve ethical standards that are as high as scientific standards. Thirdly, as it is unlikely that an overall universal SOC can be rapidly achieved in research projects in developing countries, the goal should be to implement reasonable standards that are significantly higher than available in the host country, and closer to standards in the sponsoring country. Fourthly, these ideas should be applied in a way that progressively ratchets SOC upwards, both for subsequent research projects and for the benefit of the local system through genuine partnerships and capacity building, leaving participants and their communities better off after the trial and not merely "no worse off". ${ }^{7}$ The process of moral reasoning will also be sharpened by grappling with these difficult issues. Considerations of context, safety, logistics, harm, dignity, respect, and benefit within a particular setting are crucial to making moral progress.

\section{CONCLUSIONS}

We hope that this discussion illustrates that the notion of standard of care is more complex and should be more inclusive than has generally been conceded in recent debates. Honesty requires acknowledgement that high standards could be progressively attained. If the broader conception of SOC outlined above is coupled to improving public healthcare services, both the research endeavour and the communities in dire need will benefit. Finally, capacity building, empowerment, and a broader moral agenda for health are essential if the morality of research ethics is to be shifted towards a new 
paradigm that inspires researchers and sponsors, and serves public and global health aspirations.

\section{Authors' affiliations}

K Shapiro, Family Health International, PO Box 13951, Research

Triangle Park, NC, USA

S R Benatar, Department of Medicine and Bioethics Centre, University of Cape Town Observatory, 7925, Cape, South Africa

The HIV Prevention Network and Family Health International funded our work.

Members of the HIV Prevention Trials Network Ethics Working Group: Q A Karim (Chair), R Bayer, S R Benatar, M Chigwanda, D Dixon, D Donnell, L Guay, S Kirkendale, B Lo, K MacQueen, S M Monico, V Muthuswamy, K Shapiro, R Strauss, S Wakefield, and C Woodsong.

\section{REFERENCES}

1 AIDS Epidemic Update 2003. Joint United Nations Programme on HIV/AIDS Geneva, Switzerland, 25 November 2003

2 Human Development Report 1991. New York: Oxford University Press, 1991

3 Benatar SR. Global disparities in health and human rights. Am J Public Health 1998;88:395-400.

4 Benatar SR, Singer PA. A new look at international research ethics. BMJ 2000;321:824-6.

5 London AJ. The ambiguity and the exigency: clarifying "standard of care" arguments in international research. J Med Philos 2000;25:379-97.

6 London AJ. Equipoise and international human-subjects research. Bioethics 2001; 15:312-32

7 CIOMS. International Ethical Guidelines for Biomedical Research Involving Human Subjects. Geneva: CIOMS. 2002.

8 MacQueen KM, Shapiro K, Abdool KQ, et al. Ethical challenges in international HIV prevention research. Account Res 2004:11:49-61.

9 Kass N, Hyder AA. Attitudes and experiences of US and developing country investigators regarding US human subject regulations. Ethical and Policy Issues in International Research: Clinical Trials in Developing Countries. Volume II, B 1-158. Bethesda MA: National Bioethics Advisory Commission, 2001.

10 National Bioethics Advisory Committee. Ethical and Policy Issues in International Research: Clinical Trials in Developing Countries. Bethesda MA National Bioethics Advisory Commission, 2001.

11 World Medical Association Declaration of Helsinki, Ethical Principles for Medical Research Involving Human Subjects, 52nd WMA General Assembly. Edinburgh, Scotland: October, 2000.

12 Ethical considerations in HIV preventive vaccine research. UNAIDS guidance document. Geneva: UNAIDS, 2000

13 Nuffield Council on Bioethics. The ethics of research related to healthcare in developing countries. London: Nuffield Council on Bioethics, 2002.

14 Belsky L, Richardson HS. Medical researchers' ancillary care responsibilities. BMJ 2004;328: 1494-8.

15 Beauchamp TL, Childress JF. Principles of Biomedical Ethics, 5th edn. New York: Oxford University Press, 2001.

16 Benatar SR. Reflections and recommendations on research ethics in developing countries. Soc Sci Med 2002;54:1131-4.

17 Pogge T. World poverty and human rights: cosmopolitan responsibilities and reforms. Cambridge UK: Polity Press, 2002

18 Rivera R, Borasky D, Rice R, et al. Research Ethics Training Curriculum. Family Healthy International. NC, USA: Research Triangle Park, 2001.

19 Singer P. Famine, affluence, and morality. Philos Public Affairs 1972;1:229-43.
20 Iglehart J. American health services: expenditure. N Engl J Med 1999;340:70-6.

21 Farmer P. Social inequalities and emerging infectious diseases. Emerg Infect Dis 1996;2:259-69.

22 Guay LA, Musoke P, Fleming T, et al. Intrapartum and neonatal single-dose nevirapine compared with zidovudine for prevention of mother-to-child transmission of HIV-1 in Kampala, Uganda: HIVNET 012 randomized trial. Lancet 1999:354:795-802.

23 Call to Action Project. A Global Program to Prevent Mother-to-Child Transmission of HIV. Elizabeth Glaser Pediatric AIDS Foundation, www.pedaids.org/fs_projects/html (accessed 6 October 2004).

24 Grosskurth H, Mosha F, Toddx J, et al. Impact of improved treatment of sexually transmitted diseases on HIV infection in rural Tanzania: randomized controlled trial. Lancet 1995;346:530-6.

25 Benatar SR. Justice and medical research: a global perspective. Bioethics $2001 ; 15: 333-40$

26 Community Working Group. HIV Trial Prevention Network. Available at www.hptn.org/community_program/community_working_group.asp (accessed 6 October 2004).

27 Lo B, Bayer R. Establishing ethical trials for treatment and prevention of AIDS in developing countries. BMJ 2003;327:337-9.

28 Family Health International Research Ethics Training Curriculum. Available at www.fhi.org/en/RH/Training/trainmat/ethicscurr/index.htm (accessed 6 October 2004).

29 MacQueen K, Sugarman J. HPTN Ethical Guidance for Research. January 2003, www.hptn.org/ResearchEthics/HPTN_Ethics_Guidance.htm (accessed 6 October 2004).

30 Campaign For Access to Essential Medicines. Médecins Sans Frontières http://www.accessmed-msf.org/ (accessed 6 October 2004).

31 A Commitment to Action for Expanded Access to HIV/AIDS Treatment. International HIV Treatment Access Coalition. Geneva: WHO, December 2002.

32 WHO announcement of 3 by 5 . The 3 by 5 initiative. http://www.who.int/ 3 by $5 /$ en (accessed 6 October 2004).

33 US Department of State. The President's Emergency Plan for AIDS Relief. www.state.gov/s/gac/ (accessed 5 May 2004).

34 Wiktor SZ, Sassan-Morokro M, Grant AD, et al. Efficacy of trimethoprimsulphamethoxazole prophylaxis to decrease morbidity and mortality in HIV-1infected patients with tuberculosis in Abidjan, Cote d'Ivoire. Lancet 1999;353:1469-75.

35 Coverage of selected health services for HIV/AIDS prevention and care in less developed countries in 2001. World Health Organization, November 2002.

36 Access to Prevention: Closing the Gap, Report of the Global HIV Prevention Working Group, May 2003. Available at www.kff.org/hivaids/ hivghpwgpackage.cfm (accessed 6 October 2004).

37 Treating 3 million by 2005, Making it happen, the WHO strategy. Geneva: WHO/UNAIDS, 2003.

38 Fitzgerald DW, Pape JW, Wasserheit JN, et al. Provision of treatment in HIV1 vaccine trials in developing countries. Lancet 2003:362:993-4.

39 Tucker T, Slack C. Not if but how? Caring for HIV-1 vaccine trial participants in South Africa. Lancet 2003;362:995.

40 de Zoysa I, Christopher E. Ethical challenges in efficacy trials of vaginal microbicides for HIV prevention. Am J Public Health 1998:88:571-5.

41 Elias CJ, Heise LL. Challenges for the development of female-controlled vaginal microbicides. AIDS 1994;8:1-9.

42 Fitzgerald DW, Behets FM-T. Womens' health and human rights in HIV prevention research. Lancet 2003;361:68-9.

43 Kahn JP, Mastrioanni AC, Sugarman JP. Beyond consent: seeking justice in research. New York: Oxford University Press, 1998.

44 Bringing vaccines to Soweto: An interview with Glenda Grey, January, 2003. International AIDS Vaccine Initiative, info@iavi.org laccessed 6 October 2004).

45 Sachs J. Macroeconomics and Health: investing in health for economic development. Report of the Commission on Macroeconomics and Health Geneva: WHO, 2001 